\title{
Neonatal transitional support with intact umbilical cord in assisted vaginal deliveries: a quality-improvement cohort study
}

\author{
Elisabeth Sæther ${ }^{1 *} \mathbb{D}$, Friedrich Reinhart-Van Gülpen ${ }^{2}$, Christer Jensen ${ }^{3,4}$, Tor Åge Myklebust ${ }^{5}$ and
} Beate Horsberg Eriksen ${ }^{2}$

\begin{abstract}
Background: Deferring cord clamping has proven benefits for both term and preterm infants, and recent studies have demonstrated better cardio-respiratory stability if clamping is based on the infant's physiology, and whether the infant has breathed. Nevertheless, current guidelines for neonatal resuscitation still recommend early cord clamping (ECC) for compromised babies, unless equipment and competent personnel to resuscitate the baby are available at the mother's bedside. The objective of this quality improvement cohort study was to evaluate whether implementing a new delivery room protocol involving mobile resuscitation equipment (LifeStart ${ }^{\mathrm{TM}}$ ) reduced the prevalence of ECC in assisted vaginal deliveries.
\end{abstract}

Methods: Data on cord clamping and transitional care were collected 8 months before and 8 months after implementing the new protocol. The Model for Improvement was applied to identify drivers and obstacles to practice change. Statistical Process Control analysis was used to demonstrate signals of improvement, and whether these changes were sustainable. Multivariate logistic regression was used to evaluate the impact of the new protocol on the primary outcome, adjusted for possible confounders.

Results: Overall prevalence of ECC dropped from 13 to $1 \%(P<0.01)$, with a $98 \%$ relative risk reduction for infants needing transitional support on a resuscitation table (adjusted OR 0.02, $P<0.001$ ). Mean cord clamping time increased by $43 \%(p<0.001)$. Although fewer infants were placed directly on mothers' chest $(n=43[42 \%]$ vs $n=69$ $[75.0 \%], P<0.001)$, there were no significant differences in needs for immediate transitional care or transfers to Neonatal Intensive Care Unit. A pattern of improvement was seen already before the intervention, especially after mandatory educational sessions and cross-professional simulation training.

Conclusions: A new delivery-room protocol involving mobile resuscitation equipment successfully eliminated early cord clamping in assisted vaginal deliveries of term and near-term infants. A systematic approach, like the Model for Improvement, seemed crucial for both achieving and sustaining the desired results.

Trial registration: The study was approved as a service evaluation as defined by the Regional Committee for Medical and Health Research Ethics (2018/1755/REK midt).

Keywords: Umbilical cord clamping, Infant, Resuscitation, Assisted vaginal delivery

\footnotetext{
* Correspondence: elisabeth.sether@helse-mr.no

'Department of Obstetrics and Gynecology, Møre and Romsdal Hospital

Trust, Åsehaugen 5, N-6017 Ålesund, Norway

Full list of author information is available at the end of the article
}

(c) The Author(s). 2020 Open Access This article is licensed under a Creative Commons Attribution 4.0 International License, which permits use, sharing, adaptation, distribution and reproduction in any medium or format, as long as you give appropriate credit to the original author(s) and the source, provide a link to the Creative Commons licence, and indicate if changes were made. The images or other third party material in this article are included in the article's Creative Commons licence, unless indicated otherwise in a credit line to the material. If material is not included in the article's Creative Commons licence and your intended use is not permitted by statutory regulation or exceeds the permitted use, you will need to obtain permission directly from the copyright holder. To view a copy of this licence, visit http://creativecommons.org/licenses/by/4.0/ The Creative Commons Public Domain Dedication waiver (http://creativecommons.org/publicdomain/zero/1.0/) applies to the data made available in this article, unless otherwise stated in a credit line to the data. 


\section{Background}

Optimal timing of umbilical cord clamping has been debated for centuries, and definitions vary [1]. "Early" cord clamping (ECC) is generally done before one minute after birth (commonly 15-30 seconds), whereas "delayed" cord clamping (DCC) refers to later than $1 \mathrm{mi}$ nute, or when cord pulsations have ceased [2]. Historically, doctors and midwives have defined ECC as malpractice, associated with risk and harm for both mother and infant [3].

In Norway, DCC was the norm in midwife-lead deliveries until late 1990s. In many hospitals, a shift followed the introduction of STAN ${ }^{\text {sx }}$ technology for continuous foetal heart rate monitoring. The user manual recommended immediate "double-clamping" of the umbilical cord before the baby's first breath (ICC) to obtain correct cord blood samples for blood gas analysis [4]. Quickly, cord blood analysis became a quality benchmark, recommended for all deliveries [5]. Despite evidence supporting sampling from a pulsating cord [6], many institutions still practice ICC, especially in assisted vaginal deliveries (ventouse-, forceps- or breech) and caesarean sections [7].

A growing body of evidence calls for abandoning ECC $[8,9]$. The World Health Organization (WHO) recommends DCC (at least $1 \mathrm{~min}$ ), unless concern about mother or baby [10]. ECC is recommended if the baby needs to be moved for resuscitation. However, cardiorespiratory support may be initiated with an intact umbilical cord, provided that competent personnel and equipment are available at the mother's bedside [10]. This corresponds with international guidelines on neonatal resuscitation and transitional care [11, 12]. When DCC is not feasible, umbilical cord milking (UCM) has been suggested as a safe alternative for infants with gestational age 29 weeks or more $[13,14]$.

Research on infant transitional physiology underpins the importance of maintaining vital parameters like blood pressure, organ perfusion and oxygen saturation during the first minutes of life $[15,16]$. This urges a new look on how babies at risk are handled in the delivery rooms [17]. Experts argue that these infants would be better off if respiratory support were provided with the umbilical cord intact [18]. Immediate cord clamping is a non-physiological intervention that blocks venous return from the placenta to the baby's heart and obstructs umbilical arteries, thus reducing preload and increasing afterload and peripheral vascular resistance, resulting in reduced cardiac output [19].

New research shows that both venous and arterial umbilical flow is unrelated to cessation of pulsations, with large individual variations [20]. Researchers argue that cord clamping should be based on the infants' physiology rather than a fixed period of time [15].
Randomized controlled trials (RCT) suggest benefits of waiting longer than 2-3 min. For term infants, studies have found increased iron stores and brain myelinisation [21], better oxygenation and perfusion of vital organs with DCC [22].

Most trials comparing cord clamping practices exclude complicated vaginal deliveries and babies needing resuscitation, whereby conclusions cannot be drawn for these situations [10, 23]. Assisted vaginal deliveries are often complicated by intrapartum events like foetal asphyxia, umbilical cord compression or shoulder dystocia, frequently delivering compromised and hypovolemic babies. To move the baby for ventilation support or resuscitation, the umbilical cord must be cut; although the essential needs are volume and oxygen, both readily available via the placenta and umbilical cord [24, 25].

However, ventilation support and full resuscitation can be done without separating mother and baby $[22,26]$. For hospital settings, mobile bed-side resuscitation equipment (ex. LifeStart ${ }^{\mathrm{tm}}$, Concord ${ }^{\mathrm{mm}}$ ) has been developed and tested in different settings with positive results, and is welcomed by both parents and health care professionals [27-29]. Early skin-to-skin-contact and the familiar voice and touch of the mother is shown to improve transition and reduce stress, even when transitional support is needed [30]. Experts argue that separation of infants from their mothers at birth is no longer acceptable [31], and that delivery rooms should be furnished to secure optimal contact between mothers and infants [32].

The Medical Birth Registry of Norway does not require documentation of cord clamping time in birthrecords. Therefore, institution statistics on cord clamping practices are not available. After implementation of an evidence-based guideline for DCC at our specialised (level one) obstetric unit, compliance was tested by measuring the time from delivery to cord clamping in all deliveries during March, 2017. A Patient-Safety and Quality Improvement Project was introduced, aiming to ensure optimal cord clamping for all infants.

Consequently, as a continuation of the quality improvement (QI) initiative and with support from the above mentioned evidence, the objective of this study was to evaluate whether implementing a new deliveryroom protocol involving a mobile resuscitation trolley $\left(\right.$ LifeStart $\left.{ }^{\mathrm{m}}\right)$ reduced the prevalence of ECC in assisted vaginal deliveries.

\section{Methods}

\section{Study design}

We conducted a quality improvement cohort QI study of cord clamping practice in assisted vaginal deliveries. The study consisted of two phases: A baseline 8-month period (Period 1), where standard care was applied (March 1st to October 31st 2017), followed by an 8- 
month intervention-period (Period 2), where the new protocol and resuscitation equipment were implemented (November 1st 2017 to June 30th 2018). We used anonymous data from the previously described Patient Safety and Quality Improvement Project. The study was approved as a service evaluation as defined by the Regional Committee for Medical and Health Research Ethics (2018/1755/REK midt), and waiver of individual patient informed consent was granted. It was approved by the Director of Clinic for Women, Children and Adolescents, Møre and Romsdal Hospital Trust, and by the institution's Privacy Ombudsman (ephorte reference 2018/1357-10).

\section{Setting}

The study was performed at Clinic for Women, Children and Adolescents, Møre and Romsdal Hospital Trust, Ålesund, Norway. At this clinic, low-risk deliveries are midwife-led, whereas complicated deliveries are led by teams consisting of an obstetrician, an obstetric registrar and a midwife. A Neonatal Intensive Care Unit (NICU) facilitates care for sick and premature infants. Whenever possible, the collaborative conduct of assisted vaginal deliveries is planned prior to delivery with a paediatric team (paediatric registrar and neonatal intensive care nurse), expected to be present in the delivery room and responsible for initial assessment and treatment of the infant. An evidence based protocol of delayed cord clamping was introduced in 2009.

\section{Standard care (Period 1)}

Risk assessments and differentiation of care were guided by national clinical standards, and done during pregnancy, at patient admission and during labour. Preparations in the delivery room were done accordingly. Paediatric team was alarmed when breech birth was imminent, or decision of instrumentation was made. A resuscitation table (Cosy-Cot ${ }^{\mathrm{Tm}}$, Fisher \& Paykel Healthcare, Auckland, NZ) was brought into the room and placed opposite to the birthing bed.

Delayed cord clamping was attempted in all deliveries, while providing essential care. An assistant midwife obtained arterial and venous cord blood gases from a pulsating cord within the first 30-40 s. Apgar Scores were evaluated after 1, 5 and $10 \mathrm{~min}$ by the paediatric team. Neonatal resuscitation algorithm was applied [33].

If the infant was compromised and not recovering during the first $30-60 \mathrm{~s}$, the umbilical cord was cut at least $30 \mathrm{~cm}$ from the umbilicus, and the infant was moved to the resuscitation table for further assessment and care. Cord clamping time was recorded by an assistant nurse, using a digital clock in the delivery room. If the infant did not respond to initial stimulation, umbilical cord milking (UCM) 3-5 times towards the umbilicus was recommended to expedite placental transfusion, or as a substitute for DCC. Preheated linen and an overhead warmer protected the infant from hypothermia. Ventilation support was provided with a T-piece resuscitator (NeoPuff Infant Resuscitator $^{\mathrm{Tx}}$, Fisher \& Paykel, Auckland, NZ). Suction equipment (AGA MS-33 Suction Ejector ${ }^{\text {TM }}$, AGA - Linde Healthcare, Oslo, Norway) was applied if necessary. Ventilation support was initiated with room air, controlled by a gas flowmeter (Low-flow Air-Oxygen Blender ${ }^{\mathrm{Tm}}$, Ohio Medical Corporation, Gurnee, US). Oxygen fraction was increased according to protocol. Pulse oximetry (Nellcor ${ }^{\text {ru }}$ OxiMax N-65, Covidien, Boulder CO, US) was recommended. Once stabilized, infants were placed skin-to-skin on the mother's chest and covered.

\section{New delivery-room protocol (Period 2)}

Preparations, initial assessment and care were provided as described for period 1 . In addition, a mobile resuscitation trolley, LifeStart ${ }^{\text {TM }}$ (Inspiration Health Care Ltd. Leicestershire, UK) was placed next to the birthing bed. The trolley was tubed to central supplies of air and oxygen, and fully equipped with a T-piece resuscitator, Oxi-blender and suction equipment to facilitate bed-side transitional support and resuscitation. A heating mattress, Cosy-Therm ${ }^{\mathrm{Tm}}$ (Inspiration Health Care Ltd. Leicestershire, UK) was used for prevention of hypothermia.

Equipment for assisted vaginal delivery was set up on the opposite side of the birthing bed to avoid logistic problems. If non-vigorous immediately after birth, infants were placed on LifeStart ${ }^{\mathrm{Tm}}$ for drying, stimulation and further assessment. The algorithm for resuscitation of the newborn by the Norwegian Resuscitation Council (NRR) was applied [33], and modified to include transitional support with intact umbilical cord (Fig. 1). UCM was recommended as described for Period 1. Any ventilation support or resuscitation was initiated with intact umbilical cord. Surveillance by pulse oximetry was recommended. Self-breathing and crying infants were placed directly on mothers' chest. If the umbilical cord was very short, the trolley was placed as close to the mother's vagina as possible, otherwise the trolley was placed perpendicular to the birthing bed.

The umbilical cord was cut no earlier than one minute after delivery of the infant; preferably after cease of pulsations or when the cord had turned white. Cord clamping time was recorded. In the event of obstetric emergency requiring better access to the mother, plans were made for how to move the paediatric team quickly. Once stabilized and self-breathing, the infants were placed skin-to-skin with their mothers and covered. 


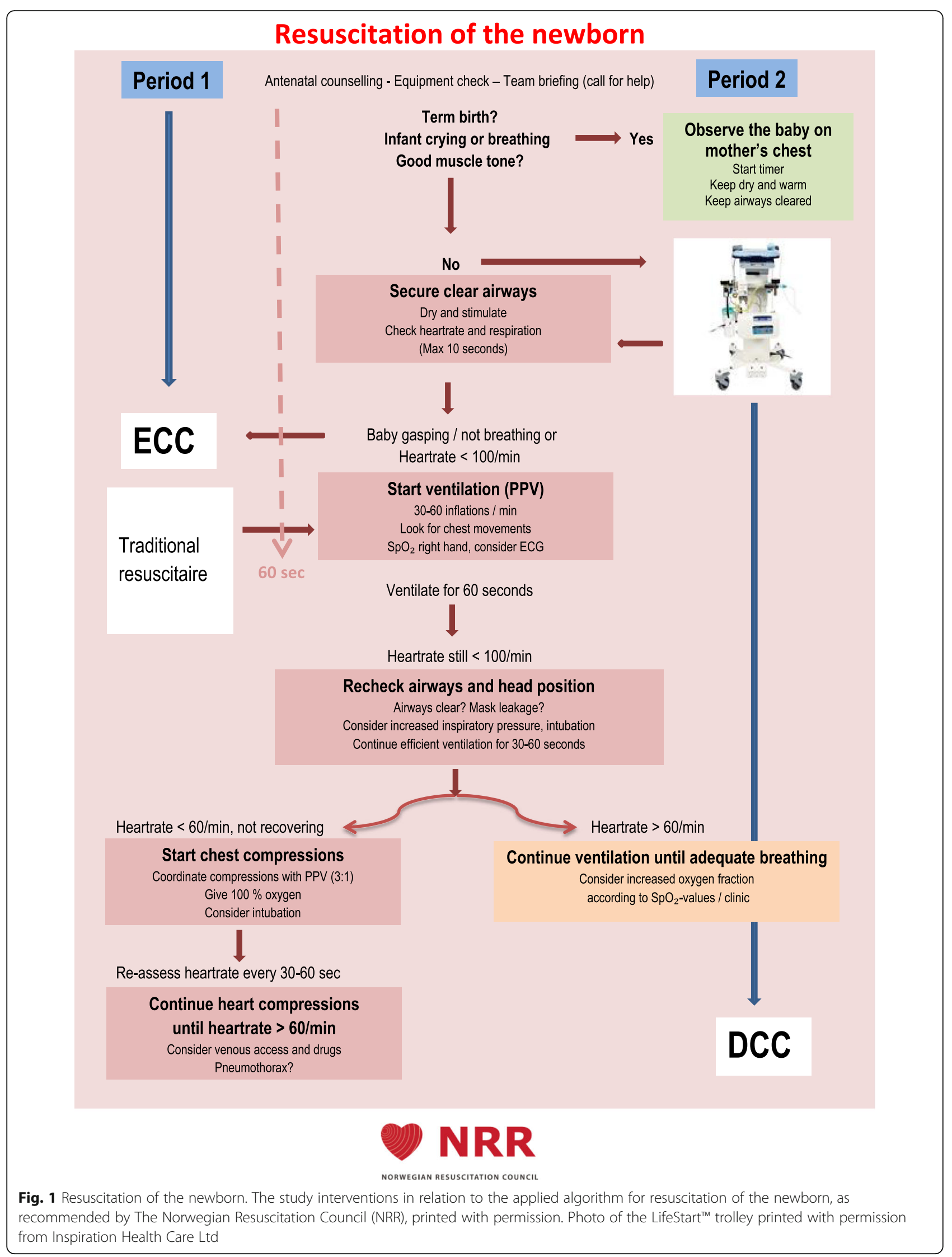




\section{Inclusion}

Live-born singletons with gestational age (GA) ranging from $36+0$ to $43+0$ weeks, subject to assisted vaginal delivery (ventouse, forceps or breech), born in the delivery unit during periods 1 and 2 were eligible for inclusion in the QI-project. Vaginal twin deliveries and any converts to emergency caesarean section were excluded.

\section{Data collection}

Data was collected for all consecutive births meeting inclusion criteria. Electronic birth records lacked data on cord clamping; hence data was collected manually for the QI-project. A paper-based form was already routinely in use; collecting data like exact time of birth, birthweight, Apgar scores; serving as support for the subsequent electronic documentation. It was modified to include data on parity, gestational age, delivery mode, indications for assisted delivery and intact cord blood gases. In cases of ECC, attending midwives were asked to fill in indication and whether the cord was milked or not.

For the QI-project, relevant data was registered in an Excel spread-sheet. Once registered, forms were shredded. Data from all deliveries meeting inclusion criteria was extracted from the QI-project data-file and prepared for this study by the QI-project leader. Data on adverse events were extracted from the hospital's incident reporting system.

\section{Primary outcome}

Prevalence of early cord clamping (ECC)

\section{Secondary outcomes}

- Apgar score at 1,5 and 10 min after birth

- Placement of the infant the first minute after birth (resuscitation table or mother's chest

- Immediate care of the infant (stimulation/drying, heat-loss prevention, pulse-oximetry)

- Rectal temperature at 10-20 min

- Need for ventilation support

- Need for full resuscitation (chest compressions and positive pressure inflation)

- Transfer to NICU (birth-related reasons).

- Adverse events

\section{Study of the intervention}

The Model for Improvement by Langley [34] was applied in both study periods, representing a theoretical and practical framework for the QI-project. The model's major tenets are: Setting time-specific and measureable aims, establishing measures to determine if a specific change leads to an improvement, selecting changes that will result in improvement and testing the changes by conducting Plan-Do-Study-Act (PDSA) cycles in a real work setting.

After baseline testing of adherence to cord clamping protocol, an operational target of maximum 2\% ECC in vaginal deliveries by November 1st, 2017 was set by the QI-project team. Starting in March, 2017, several PDSAcycles were carried out to support the improvement efforts.

Identification of drivers and obstacles revealed a gap of knowledge about the benefits of DCC and support of transition with an intact umbilical cord. Thus, building a common knowledge base through cross-professional educational sessions was prioritized. Repeated 1-h standardized presentations of the theoretical rationale was directed by the QI-project team (midwife, neonatologist and NICU-nurse). Cross-professional participation was encouraged to broaden perspectives in plenum discussions. Clinical and practical questions were welcomed and addressed.

Prior to implementation of the new protocol and equipment, mandatory training for all involved personnel was seen as essential to reduce the chances of technical and operational failure or adverse events at the set-out. Training included 1 -h theoretical and practical demonstration of set-up and operation of LifeStart ${ }^{\mathrm{Tx}}$ and associated resuscitation equipment, followed by $2-\mathrm{h}$ simulation training in situ. Simulation included debriefing focusing on inter-disciplinary collaboration and communication. During this preparation, the new delivery room protocol was adjusted according to continuous feedback from discussions and inter-disciplinary hearings.

After implementing the new protocol and equipment, re-education to all involved personnel was offered at several occasions, including brief lectures in the delivery unit and NICU, posters and short simulation sessions. Continuous feedback was welcomed, in order to rule out deviations such as procedural misunderstandings, user errors and technical difficulties. The protocol was again modified, and involved personnel updated, accordingly.

To establish whether the observed outcomes were due to implementation of the new protocol and equipment, or were already detectable before this, variation in cord clamping time was monitored during both study periods, using Statistical Process Control (SPC) analyses [35]. Run charts were used to demonstrate signals of improvement, and whether changes lead to improvement over time. Performance was displayed on an Improvement Board in the delivery unit, for transparency and motivation.

\section{Statistical analyses}

IBM SPSS Statistics software, version 23 was applied for all statistical analysis. $P$-values less than 0.05 were 
considered to indicate statistical significance. Univariate analyses were performed to identify differences in background variables and cord clamping variables between periods 1 and 2 . Continuous variables were compared by using the Mann-Whitney U test or Student's t-test as appropriate. Categorical / dichotomous variables were compared by using Pearson's Chi-square $\left(\mathrm{x}^{2}\right)$ test or Fischer's exact test as appropriate.

Multivariate logistic regression analysis was used to assess the impact of the new delivery room protocol on the prevalence of early cord clamping, adjusted for possible confounding factors. Unadjusted and adjusted odds ratios (OR) were presented with 95\% confidence intervals (CI).

The Run Chart was created using Microsoft Excel and analysed using the median and standard run chart evaluation rules. According to the user manual [36], a "shift" represents a period where six or more consecutive points all fall above or below the median, whereas a "trend" occurs when five or more consecutive points all rise or fall.

\section{Results}

During the QI-project, 905 live infants were born in period 1, compared to 864 in period 2 . Of these, 93 were singletons with $\mathrm{GA} \geq 36$ completed weeks and subject to assisted vaginal delivery in period 1 , versus 119 in period 2. A flow chart of inclusion is shown in Fig. 2. A closer investigation of the data revealed 17 protocol violations (assigned protocol not applied). In period 1, this was a case where LifeStart ${ }^{\mathrm{Tn}}$ was applied before the agreed start-up date. In period 2, violations included: No time for set-up (3), paediatrician declined (9), LifeStart ${ }^{\text {tm }}$ not available (3), suction equipment failure (1). All these cases were excluded from statistical analysis.

A total of 195 cases were eligible for statistical analyses in periods $1(n=92)$ and $2(n=103)$. The characteristics of these are shown in Table 1.

There were no significant differences in most background variables, except from mean birthweight. At this institution, the preferred method for instrumentation in assisted vaginal deliveries is ventouse. None of the

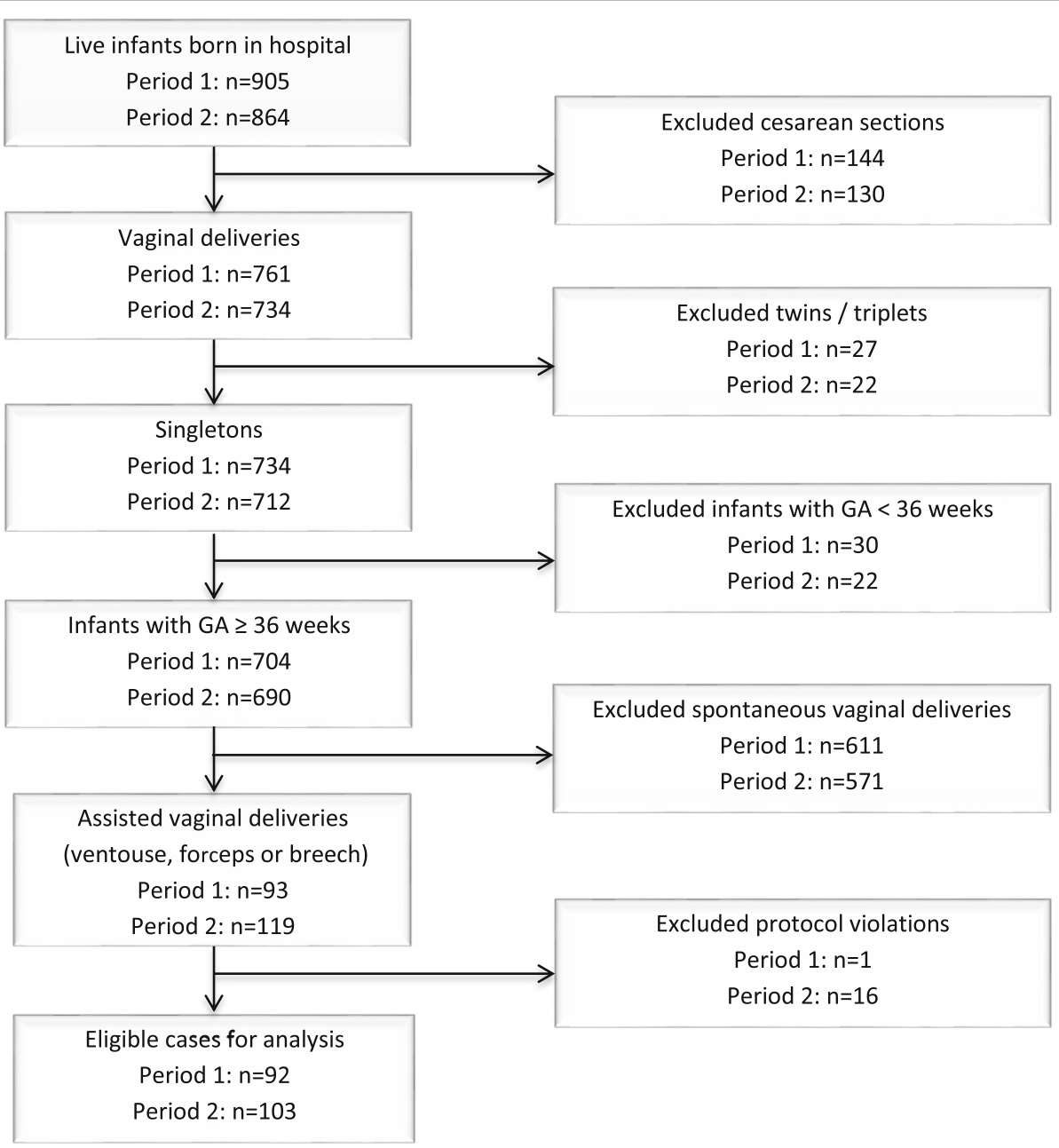

Fig. 2 Flow-chart of inclusion of study population 
Table 1 Background characteristics of mothers and infants

\begin{tabular}{|c|c|c|c|}
\hline & Period $1(n=92)$ & Period $2(n=103)$ & $P$-value \\
\hline Nulliparous & $66(71.7)$ & $74(71.8)$ & $0.99^{\mathrm{a}}$ \\
\hline Gestational age (weeks) & $40.1 \pm 1.3$ & $39.9 \pm 1.3$ & $0.21^{\mathrm{b}}$ \\
\hline Birthweight (g) & $3676 \pm 570$ & $3508 \pm 437$ & $<0.01^{c}$ \\
\hline \multicolumn{4}{|l|}{ Delivery mode } \\
\hline Ventouse & $85(92.4)$ & $94(91.3)$ & $0.77^{\mathrm{a}}$ \\
\hline Forceps & $2(2.2)$ & $2(1.9)$ & $1,00^{\mathrm{b}}$ \\
\hline Breech (Lövset's manoeuvre) & $5(5.4)$ & $7(6.8)$ & $0.69^{\mathrm{a}}$ \\
\hline \multicolumn{4}{|l|}{ Indications, assisted delivery } \\
\hline Suspect asphyxia ${ }^{e}$ & $50(54.3)$ & $61(59.2)$ & $0.49^{\mathrm{a}}$ \\
\hline Maternal $^{f}$ & $37(40.2)$ & $36(35.0)$ & $0.45^{\mathrm{a}}$ \\
\hline Breech presentation & $5(5.4)$ & $7(6.8)$ & $0.69^{a}$ \\
\hline Cord blood gases, artery & $73(79.3)$ & $83(80.6)$ & \\
\hline Arterial pH & $7.20 \pm 0.1$ & $7.20 \pm 0.1$ & $0.81^{c}$ \\
\hline Arterial $\mathrm{PCO}_{2}(\mathrm{kPa})$ & $7.34 \pm 1.4$ & $7.30 \pm 1.3$ & $0.86^{c}$ \\
\hline Arterial base deficit (mmol/l) & $5.93 \pm 2.9$ & $5.84 \pm 2.9$ & $0.84^{c}$ \\
\hline Cord blood gases, vein & $82(89.1)$ & $98(95.1)$ & \\
\hline Venous pH & $7.32 \pm 0.1$ & $7.33 \pm 0.1$ & $0.64^{c}$ \\
\hline Venous $\mathrm{PCO}_{2}(\mathrm{kPa})$ & $5.08 \pm 1.0$ & $5.05 \pm 1.0$ & $0.80^{c}$ \\
\hline Venous base deficit (mmol/l) & $5.72 \pm 2.5$ & $5.47 \pm 2.5$ & $0.53^{c}$ \\
\hline Metabolic acidosis ${ }^{9}$ & $0(0)$ & $1(0.9)$ & $1.00^{\mathrm{d}}$ \\
\hline \multicolumn{4}{|l|}{ Apgar scores } \\
\hline $1 \mathrm{~min}$ & $8(6.25-9)$ & $8(7-9)$ & $0.89^{b}$ \\
\hline $5 \mathrm{~min}$ & $9(9-10)$ & $9(9-10)$ & $1.00^{\mathrm{b}}$ \\
\hline $10 \mathrm{~min}$ & $10(9-10)$ & $10(9-10)$ & $0.73^{b}$ \\
\hline
\end{tabular}

The results are reported as frequency (percentage), mean \pm standard deviation (SD), median (inter-quartile range (IQR))

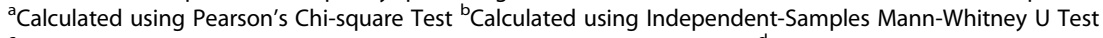

${ }^{\mathrm{c} C a l c u l a t e d}$ using Independent samples T-test, equal variances assumed. ${ }^{\mathrm{d}}$ Calculated using Fisher's Exact Test

${ }^{\mathrm{e}}$ Based on information from continuous foetal monitoring (CTG alone or CTG with ST-analysis)

fProlonged 2nd stage, maternal exhaustion, hypertension / pre-eclampsia

${ }^{9}$ Defined as arterial $\mathrm{pH}<7.00$ and arterial base deficit $\geq 12 \mathrm{mmol} /$ liter

Table 2 Comparison of cord clamping variables and indications for ECC

\begin{tabular}{llll}
\hline & Period 1 $(n=92)$ & Period 2 $(n=103)$ & $P$-value \\
\hline Cord clamping time in seconds & $320 \pm 243$ & $457 \pm 375$ & $<0.001^{\mathrm{a}}$ \\
$<60 \mathrm{~s}$ (ECC) & $12(13.0)$ & $1(1.0)$ & $<0.01^{\mathrm{b}}$ \\
$60-179 \mathrm{~s}$ (IMCC) & $12(13.0)$ & $3(2.9)$ & $<0.01^{\mathrm{b}}$ \\
$\geq 180 \mathrm{~s}$ (DCC) & $68(73.9)$ & $99(96.1)$ & $<0.001^{\mathrm{b}}$ \\
Umbilical cord milking (UCM) & $9(9.8)$ & $4(3.8)$ & $0.10^{\mathrm{b}}$ \\
Indications for ECC & $(n=12)$ & $(\mathrm{n}=1)$ & $0.47^{\mathrm{c}}$ \\
None / tradition & $1(1.1)$ & $0(0)$ & $<0.001^{c}$ \\
Infant moved to resuscitation tabled & $11(12.0)$ & $1(1.0)$ & $1.00^{c}$ \\
Cord problems & $0(0)$ & $0(0)$ & \\
Maternal complications & $0(0)$ &
\end{tabular}

The results are reported as mean \pm standard deviation (SD), frequency (percentage)

${ }^{a}$ Calculated using Independent samples T-test, equal variances not assumed

${ }^{\text {b} C a l c u l a t e d ~ u s i n g ~ P e a r s o n ' s ~ C h i-s q u a r e ~ T e s t ~}{ }^{\mathrm{C}}$ Calculated using Fisher's Exact test

${ }^{d}$ traditional resuscitation table in period 1 , LifeStart in period 2 
breech deliveries needed instrumentation by forceps. Cord blood analyses were not complete or successful for all cases.

After implementing the new protocol, there was a significant improvement in all cord clamping variables (Table 2). Mean cord clamping time increased by $43 \%$. The main indication for ECC was the need to move infants to a resuscitation table for further assessment and care. This indication did not apply in period 2 .

The only case of ECC in period 2 was due to cord snapping when positioning the infant for transitional support. Ventilation support was given on LifeStart ${ }^{\mathrm{Tm}}$. The infant was transferred to NICU due to respiration problems and Apgar scores 5-8-8, and the case was reported as an adverse event. The other adverse event was a case of converting care from LifeStart ${ }^{\mathrm{Tm}}$ to traditional resuscitation table because of a tight cord knot. The cord was clamped at $60 \mathrm{~s}$ to move the infant for ventilation support, despite $1 \mathrm{~min}$ Apgar score of 9. The cases were investigated in order to avoid future cases, and information on proper care strategies were provided to relevant personnel.

\section{Variation in prevalence of ECC during the QI-project}

A Run Chart visualises the variation in prevalence of ECC for periods 1 and 2 (Fig. 3). The blue line reflects proportions of ECC from baseline measurement, through different QI activities to prepare for implementation of the new protocol, to completed implementation.

During simulation training, the prevalence dropped to $8.3 \%$ and further to zero, already before implementing the new protocol in November 2018. After protocol revision in December 2018, there were no cases of ECC registered. This fulfills the Run chart requirements of a "shift", indicating that the improvement was not the result of chance.

\section{Primary outcome}

Multivariate logistic regression was performed to assess the overall impact of the new delivery room protocol on the primary outcome (prevalence of ECC) when adjusted for possible confounders and mediators (Table 3). The proportion of ECC was reduced by $94 \%$ in period 2, compared with period $1(\mathrm{OR}=0.06,95 \% \mathrm{CI} 0.01-0.49$, $p<0.01)$. The only covariate reaching statistical significance was 1 -min Apgar score $\leq 5(p<0.001)$ When adjusted for, this did not alter the impact of the new delivery room protocol.

After controlling for infants placed directly on mother's chest after delivery, multivariate logistic regression was performed to assess the direct impact of the new, mobile resuscitation table (Table 4). OR's were adjusted for the same confounding factors. The likelihood of ECC for infants needing help on a resuscitation table was reduced by $98 \%$ when using LifeStart ${ }^{\mathrm{Tw}}$, compared to a traditional resuscitation Table $(\mathrm{OR}=0.02,95 \% \mathrm{CI}$ $0.00-0.16, \mathrm{p}<0.001)$. No covariates reached statistical significance.

\section{Secondary outcomes}

All infants were initially stimulated by drying and rubbing their back with preheated towels. Heat-loss prevention was also provided for all cases; in period 1 by an overhead warmer; in period 2 by a heating mattress. $20 \%$ of the infants in period 2 had pulse-oximetry attached, compared to zero in period 1. ECG-monitors were not available throughout the project. No infants needed full

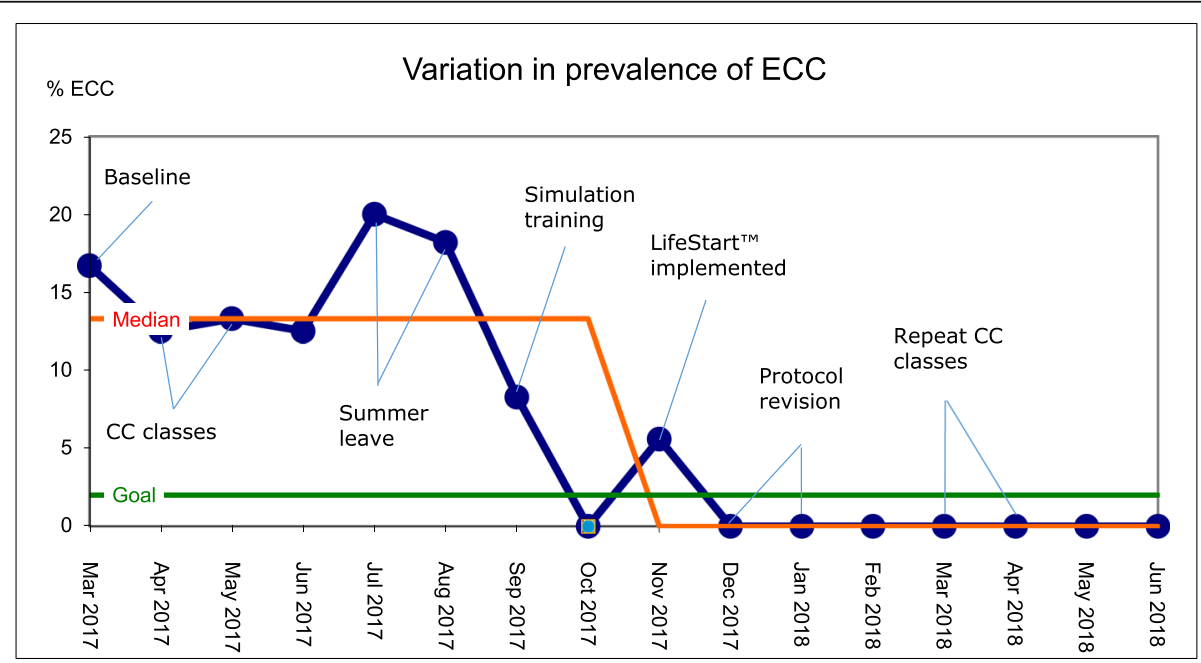

Proportion of early cord clamping in a given month during periods 1 and 2 Period 1 = Mar - Oct 2017 Period $2=$ Nov 2017 - June 2018

Fig. 3 Variation in prevalence of ECC 
Table 3 Logistic regression analyses of overall impact of the new delivery room protocol on the prevalence of ECC, adjusted for possible confounding factors

\begin{tabular}{|c|c|c|c|c|c|}
\hline Covariate & Unadjusted OR & $95 \% \mathrm{Cl}$ & Adjusted OR & $95 \% \mathrm{Cl}$ & $P$-value \\
\hline Old protocol & Ref. & & & & \\
\hline New protocol & 0.07 & $0.01-0.51$ & 0.06 & $0.01-0.49$ & $<0.01$ \\
\hline Nulliparous & 0.88 & $0.26-2.97$ & 1.54 & $0.29-8.19$ & 0.62 \\
\hline Gestational age & 1.19 & $0.75-1.87$ & 1.08 & $0.56-2.09$ & 0.81 \\
\hline Birthweight (g) & $1.00^{\mathrm{a}}$ & $1.00-1.00$ & 1.000 & $1.00-1.00$ & 0.76 \\
\hline Suspect asphyxia & 0.88 & $0.28-2.71$ & 0.84 & $0.21-3.37$ & 0.80 \\
\hline 1-min Apgar $\leq 5$ & 13.73 & $4.08-46.22$ & 17.61 & $4.46-69.50$ & $<0.001$ \\
\hline
\end{tabular}

Analysed for all assisted vaginal deliveries in periods 1 and $2(N=195)$

${ }^{a}$ differences only visible with 3 decimals

$O R$ Odds ratio $\mathrm{Cl}$ Confidence interval

resuscitation in either period. Univariate analysis showed that infants in period 2 were significantly less likely to be placed on mothers' chest (within the first minute of life), despite better 1-min Apgar scores. However, they were less likely to receive ventilation support or to be transferred to NICU (Table 5).

Infants in period 2 were less likely to have 5-min Apgar $<7$ or 10-min Apgar $<9$, but after adjusting for possible confounding factors (parity, GA, birthweight, suspect asphyxia and low 1-min Apgar score) by multivariate logistic regression analysis, no significant difference could be demonstrated for any of the short-term outcomes (Table 6). Pre-existing indications (maternal diabetes) and late-onset complications (infection, heart conditions, drugs) resulting in subsequent interventions on a resuscitation table or transfer to NICU were excluded from analysis, since this did not interfere with cord clamping practice.

\section{Discussion}

This QI cohort study demonstrates that implementing a new delivery room protocol involving a mobile resuscitation trolley $\left(\right.$ LifeStart $\left.{ }^{\mathrm{Tw}}\right)$ successfully eliminates early cord clamping in assisted vaginal deliveries. The systematic approach to practice change provided by the Model for
Improvement, seems crucial for both achieving as well as sustaining the targeted results.

The strongest effect on the prevalence of ECC was seen for infants actually placed on a resuscitation table within the first minute after birth, with a relative risk reduction of $98 \%$ when using LifeStart ${ }^{\text {tw }}$ compared to traditional equipment. At the same time, we saw an unintended and unexpected effect of the new protocol: infants were less likely to be placed directly on mother's chest after introduction of LifeStart ${ }^{\mathrm{m}}$. This included vigorous, as well as non-vigorous infants. Other studies involving mobile resuscitation equipment have not reported this [22, 37]. Several explanations may be plausible: It may reflect reactivity to the study situation, or the researcher's expectations, given that all personnel had been trained by the researcher in operating the new equipment, and was aware of being monitored with regards to protocol adherence. It may reflect novelty effects, where enthusiastic personnel finally had the opportunity to use the new equipment in real life situations. A more pragmatic explanation; given the mothers' legs placed in stirrups for delivery; may be that the mobile trolley was a convenient station to place infant when sampling for cord blood gases. Although direct skin-to-skin contact between mother and baby was

Table 4 Logistic regression analyses of the direct impact of the new, mobile resuscitation table on the prevalence of ECC

\begin{tabular}{|c|c|c|c|c|c|}
\hline Covariate & Unadjusted OR & $95 \% \mathrm{Cl}$ & Adjusted OR & $95 \% \mathrm{Cl}$ & $P$-value \\
\hline Old protocol & Ref. & & & & \\
\hline New protocol & 0.02 & $0.00-0.13$ & 0.02 & $0.00-0.16$ & $<0.001$ \\
\hline Nulliparous & 0.84 & $0.23-3.05$ & 0.44 & $0.06-3.30$ & 0.42 \\
\hline Gestational age & 1.22 & $0.74-2.01$ & 0.95 & $0.46-1.96$ & 0.89 \\
\hline Birthweight (g) & $1.001^{\mathrm{a}}$ & $1.000-1.002$ & $1.001^{\mathrm{a}}$ & $0.998-1.003$ & 0.57 \\
\hline Suspect asphyxia & 0.73 & $0.22-2.41$ & 0.63 & $0.12-3.25$ & 0.58 \\
\hline $1-\min$ Apgar $\leq 5$ & 5.40 & $1.55-18.83$ & 2.19 & $0.42-11.39$ & 0.35 \\
\hline
\end{tabular}

Analysed for all infants placed on a resuscitation table in periods 1 and $2(N=83)$

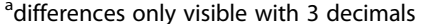

OR Odds ratio, $\mathrm{Cl}$ Confidence interval 
Table 5 Comparison of immediate transitional care and short-term outcomes for infants placed on a resuscitation table ${ }^{c}$ in periods 1 and 2

\begin{tabular}{|c|c|c|c|}
\hline Place of transitional care & Period $1(n=92)$ & Period $2(n=103)$ & $P$-values \\
\hline Infants placed on mothers chest & $69(75.0)$ & $43(41.7)$ & $<0.001^{\mathrm{a}}$ \\
\hline Infants placed on resuscitation table & $23(25.0)$ & $60(58.3)$ & $<0.001^{a}$ \\
\hline Short-term outcomes for infants placed on a resuscitation table ${ }^{c}$ & $(n=23)$ & $(n=60)$ & \\
\hline Apgar $1<5$ & $12(52.0)$ & $12(20.0)$ & $<0.01^{\mathrm{a}}$ \\
\hline Apgar $5<7$ & $4(17.4)$ & $3(5.0)$ & $0.09^{\mathrm{b}}$ \\
\hline Apgar $10<9$ & $9(39.0)$ & $9(15.0)$ & $0.05^{\mathrm{a}}$ \\
\hline Ventilation support & $15(65.2)$ & $33(55.0)$ & $0.40^{\mathrm{a}}$ \\
\hline Transfer to NICU & $6(26.1)$ & $7(11.7)$ & $0.17^{a}$ \\
\hline
\end{tabular}

The results are reported as frequency (percentage)

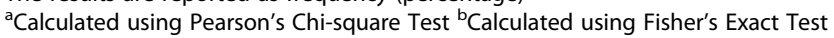
traditional resuscitation table in period 1, LifeStart in period 2

interrupted, the parents could still watch, touch and comfort their baby during transition, as valued positive in the study by Sawyer et al. [38]. An increased focus on incorporating Kangaroo Care [39] in these situations would probably have reduced separation.

In line with recent feasibility studies [22, 37], no infants were compromised enough to require full resuscitation. Many infants were stabilized after drying and stimulation only. Once on the LifeStart ${ }^{\mathrm{Tw}}$, the infants' placement was probably quite transient; since around $45 \%$ did not receive ventilation support. Rather reassuringly, infants cared for on LifeStart ${ }^{\text {tw }}$ were neither more likely to have low 5- and 10-min Apgar scores nor being transferred to the NICU for respiration problems, compared with infants placed on a traditional resuscitation table.

In this study, the proportion of infants with DCC (> $180 \mathrm{~s}$ ) increased from 74 to $96 \%$, and the mean cord clamping time increased from $5 \mathrm{~min} 20 \mathrm{~s}$ to $7 \mathrm{~min} 37 \mathrm{~s}$

Table 6 Logistic regression analyses of immediate care and short-time outcomes for infants placed on a resuscitation table ${ }^{a}$ in periods $1(n=23)$ and $2(n=60)$

\begin{tabular}{|c|c|c|c|c|c|c|}
\hline & \multicolumn{3}{|c|}{ Unadjusted estimate } & \multicolumn{3}{|c|}{ Adjusted estimate } \\
\hline & $\mathrm{OR}$ & $95 \% \mathrm{Cl}$ & $P$-value & $\mathrm{OR}$ & $95 \% \mathrm{Cl}$ & $P$-value \\
\hline Old protocol & Ref. & & & & & \\
\hline Ventilation support & 0.65 & $0.24-1.77$ & 0.40 & 1.22 & $0.38-3.97$ & 0.74 \\
\hline \multicolumn{7}{|l|}{ Low Apgar scores } \\
\hline Apgar $5<7$ & 0.25 & $0.05-1.22$ & 0.08 & 0.79 & $0.10-6.37$ & 0.82 \\
\hline Apgar $10<9$ & 0.27 & $0.09-0.82$ & 0.02 & 0.57 & $0.15-2.17$ & 0.41 \\
\hline Transfer to NICU ${ }^{b}$ & 0.37 & $0.11-1.27$ & 0.11 & 0.67 & $0.16-2.76$ & 0.58 \\
\hline
\end{tabular}

Adjusted for parity, gestational age, birthweight, suspect asphyxia and 1-min Apgar score $\leq 5$

atraditional resuscitation table in period $1(n=23)$, LifeStart in period $2(n=60)$

${ }^{b}$ due to prolonged ventilation support or unsuspected compromised infant at birth

OR Odds ratio, $\mathrm{Cl}$ Confidence interval after implementation of the new delivery room protocol. This is comparable to the results for normal vaginal deliveries during the QI-project. It exceeds the recommendations in a recent RCT including term infants, showing that a delay in cord clamping of at least 5 min results in higher iron levels, and may be beneficial for the infant's brain development due to higher myelin content [21]. It is also comparable to the mean cord clamping time found in a feasibility-RCT on term infants at risk for resuscitation [22], where infants randomized to more than five minutes delay displayed better central blood pressure and oxygen saturation of the brain.

Other researchers have suggested that using a stopwatch to time cord clamping may be inappropriate, especially in situations where infants are at risk for resuscitation. They conclude that timing should rather be based on the infant's physiology, more specifically if the infant is breathing or not $[15,18,37]$. In our study, postponing the decision to clamp the cord allowed the obstetric and paediatric teams to concentrate on the immediate medical needs of infant and mother. Timing of cord clamping was left to the discretion of midwives, whose approach for centuries has been after cease of pulsations or after delivery of the placenta.

To our knowledge, this is the first QI-study to evaluate implementation of transitional support with an intact umbilical cord in assisted vaginal deliveries specifically. Other QI-studies have focused on implementing or expanding protocols of delayed cord clamping for premature infants; reporting on the inverse outcome (prevalence of delayed cord clamping); with operational targets of $80 \%$. Achieved results vary between 53.5 and $85 \%$ [40, 41]. The current study; reporting on early cord clamping; is not directly comparable due to differences in baseline and background variables. Nevertheless, the operational target (2\% ECC) is reached faster; and seems more successfully sustained over time; as only one case of ECC was registered after implementation of 
LifeStart ${ }^{\mathrm{tw}}$. However, a pattern of improvement was detectable already before the implementation of the new protocol, most markedly following mandatory "cord clamping classes" and interdisciplinary simulation training; suggesting that increased focus alone may induce practice change. The marked increase in proportion of ECC during summer leave may reflect that $30-40 \%$ of ordinary personnel were replaced by substitutes; not necessarily well acquainted with the protocol. This underpins the necessity of continual training and education rounds to reach new employees, as highlighted in previous QI-studies [40, 41].

Other approaches to intact-cord stabilization have also been proven feasible. Batey and colleagues [42] describe how intact-cord stabilization of high-risk infants can be done either with a standard resuscitation table or the LifeStart $^{\text {ti }}$ trolley. The Baby-DUCC feasibility study [37] is another example of how this may be done. However, feedback from involved personnel in our study revealed that behind the seemingly simple intervention of moving equipment and personnel to the potentially compromised infant, lay several logistic challenges, as well as communication and collaboration issues. These issues have also been encountered by other researchers $[29,37$, 43, 44]. Examples include: ensuring availability and readiness of the equipment with several deliveries going on at the same time, collaboration and planning ahead in rapidly progressing deliveries, and how to manage space constraints at the birthing bed. Applying the Model for Improvement [34] to these challenges not only ensured a systematic approach, but also constituted a way of addressing the root causes of undesired variation.

\section{Safety issues}

This study demonstrates that transitional care and ventilation support can be done with an intact umbilical cord in assisted vaginal deliveries by moving personnel and equipment to the infant. However, the potential problem of overstretching or kinking the cord, represented by the one case of cord snapping when using mobile equipment, is a safety issue that needs to be addressed. Other researchers have also described this challenge, and how it can be overcome, for example by placing the trolley closest possible to the birth canal [37, 42].

This study implied the use of new technology under potentially urgent and stressful conditions. Considerable effort was made to ensure that all involved personnel expected to operate the trolley and associated resuscitation equipment, were trained for and confident in its use. For the project period and beyond, a standard resuscitation table was present and ready in the delivery-room in case of procedural failure. If obstetric or paediatric team was not confident about the safety of the mother or infant, they could convert to traditional care. Resuscitating an infant at the mother's bedside may also impose considerable stress on parents as well as the involved personnel. However, feedback from parents and care-providers in feasibility studies has been predominantly positive [38, 44]. For the actual setting, the major change was performing face-to-face and being able to communicate with the parents, instead of turning backs on them in the opposite end of the room. In other settings, the alternative to bed-side care may be providing care in another room, constituting a greater change for the involved personnel and possibly requiring more time to adjust.

\section{Strengths and limitations}

Choosing a QI-design for the current study was primarily done due to availability of data and funding. It may be seen as a limitation that the study lacks data on outcome parameters like infant haemoglobin, bilirubin and haematocrit, or transitional data like saturation, heartrate and expired $\mathrm{CO} 2$. It was not set up or powered to detect changes in morbidity or mortality, and data on maternal outcomes like postpartum haemorrhage or placenta problems were incomplete. However, numerous randomized controlled trials have already demonstrated the benefits of DCC and the potentially harmful effects of ECC $[8,21]$. Recent studies have supported the findings, both for vigorous and non-vigorous infants $[15,22$, 26]. This study translates the findings from previous research into clinical practice.

Analyses were done as per protocol. However, excluding protocol violations from the analyses may represent some selection bias. 16 of 17 violations happened in period 2, either because the mobile trolley was not available or set up and ready for use, or due to paediatric teams wanting to use traditional equipment instead. Three cases (one in each category) resulted in ECC. From a QI perspective; to assess whether the implementation of the new protocol was successful, these cases should perhaps have been included in the Run Chart, but they are not.

The delivery indication "suspect asphyxia" represents a known risk factor for ECC, by being closely associated with need for support on a resuscitation table. In this study, the term "suspect asphyxia" refers to a situation preceding the intervention, thereby constituting a possible confounder. Delivery room protocols, complications in 2nd and 3rd stage of labour and low 1-min Apgar scores were thought to represent potential mediators. In clinical situations, "born non-vigorous" is normally diagnosed within $10-15 \mathrm{~s}$ of life according to Neonatal Resuscitation Guidelines [11]. The decision to move the infant to a resuscitation table is frequently made within the first $30-60 \mathrm{~s}$. The on-going and 
continuous judgement of the infant's condition during the 2nd stage and upon complete delivery of the infant, culminating at actual assessment of the 1-min Apgar score, may be seen as a mediating factor influencing on caregivers' decision to clamp the cord. Second and 3rd stage complications like shoulder dystocia, cord related problems and unexpected nonvigorous infant are closely related to poor 1-min Apgar scores and may therefore represent a problem of multi-collinearity in regression analyses. Hence, data on 1-min Apgar was used as a proxy for infant complications in 2nd and 3rd stage of labour in the statistical analyses.

Health care providers' experience and confidence in neonatal transitional care, collaboration and communication between and within the obstetric and paediatric teams, and available time for planning and preparations prior to delivery may also represent confounding factors. This study did not specifically collect data on these factors, but their possible contributions are partly accounted for in the Statistical Process Control-analysis.

Upon introducing the mobile resuscitation trolley, some members of the paediatric teams raised concern about how to prevent infant hypothermia, since the trolley's only source of prevention was a heating-mattress. Pilot testing of the trolley had not reported higher rates of hypothermia for term infants [29]. For the current study, data on rectal temperature within $15 \mathrm{~min}$ after birth was initially included in the data collection plan. However, going through data from both cohorts revealed that this information was lacking in too many cases, making analysis meaningless. This is a clear limitation for analysis of short-term outcomes. On the other hand, as mentioned in the Baby-DUCC feasibility study [37], it can be argued that term and near-term infants are not the most vulnerable for hypothermia, especially not when transfused with warm blood from the placenta and dried and covered by warm towels straight after birth.

Furthermore, the study does not provide any formal evaluation of the new equipment. Prior to implementation of the new delivery room protocol, a simple questionnaire was developed, in order to get clinicians' views of the new trolley compared with traditional equipment. The questions were based on a questionnaire used in a recent feasibility trial [29]. Oral and written information about the questionnaire and its objectives was spread to all involved personnel. Despite numerous reminders, the response-rate from members of the paediatric teams (who actually operated the trolley in most cases) remained low. Instead of analysing the scarce and possibly biased material, all written feedback was incorporated in the PDSA-circles of the QI-project.

\section{Implications for the future}

Neonatal transitional support with an intact umbilical cord is suggested by WHO, provided that equipment and personnel are available at the mother's bedside [10]. In non-vigorous babies, establishing effective ventilation often takes longer than the recommended $1 \mathrm{~min}$. ECC puts the infant in an unstable situation where oxygenation may be inadequate and cardiac output compromised. This study demonstrates one way of overcoming this obstacle, whereby the benefits of placental transfusion; including oxygen, iron, nutrients and millions of stem cells are made available for infants needing it the most. The next steps should include expanding the protocol for all gestations and when caesarean sections are indicated, preferably combined with Kangaroo Care [39].

Our study has demonstrated the importance of testing and monitoring adherence to protocol in order to assess whether or not operational targets are reached and observed variation is acceptable. This requires reliable information and documentation. Reliable data is also crucial for research purposes. Currently, the Norwegian Medical Birth Registry does not require documentation on cord clamping. Hence this information is often omitted in birth records. This makes both monitoring quality and research involving cord clamping difficult. Most importantly, the possible confounding effect of different cord clamping practices cannot be controlled or adjusted for in research on short- and long-term birth-related outcomes neither for infants nor for mothers.

\section{Conclusions}

Our study demonstrates that implementing a new delivery room protocol involving mobile resuscitation equipment successfully eliminated early cord clamping in assisted vaginal deliveries. By this approach, full attention could be given to the immediate care of the infant. The decision of cord clamping could be postponed and tailored to meet the physiological needs of the infant instead of being dictated by logistics or time. The Model for Improvement appeared to be a useful tool for monitoring adherence to protocol as well as bringing about and sustaining desired change. Future protocol expansions should preferably include Kangaroo Care to avoid unnecessary separation of mothers and infants. Reliable documentation of umbilical cord clamping may help researchers and health professionals in defining optimal practice for the future.

\footnotetext{
Abbreviations

Cl: Confidence interval; DCC: Delayed cord clamping; ECC: Early cord

clamping; ECG: Electrical cardiograph; GA: Gestational age; ICC: Immediate cord clamping; IMCC: Intermediate cord clamping; NICE: National Institute for Health and Care Excellence; NICU: Neonatal Intensive Care Unit; NRR: Norwegian Resuscitation Council; OR: Odds ratio; PDSA: Plan-Do-StudyAct; PPV: Positive pressure ventilation; QI: Quality improvement;
} 
SPC: Statistical Process Control; STAN: ST-Analysis of the foetal cardiograph; UCM: Umbilical cord milking; WHO: World Health Organization

\section{Acknowledgements}

The authors thank the Director of Clinic for Women, Children and Adolescents at Møre and Romsdal Hospital Trust for inspiration and support, and the clinical staff at Department of Obstetrics and Gynecology and Department of Pediatrics for their hospitality and practical help.

\section{Authors' contributions}

ES and FRG designed the present study. ES performed data collection and wrote the manuscript. BHE, CJ and TÅM were involved in data analysis, and in revising the manuscript. All authors read and approved the final manuscript.

\section{Funding}

The data source for this research was a regional Ql-project, funded by Pasientsikkerhetsprogrammet - I trygge hender 24/7 (Regional Patient Safety Program) and Clinic for Women, Children and Adolescents, Møre and Romsdal Hospital Trust. The funders had no role in study design, data collection and analysis, decision to publish, or preparation of the manuscript.

\section{Availability of data and materials}

The datasets used during the current study are available from the corresponding author on reasonable request.

\section{Ethics approval and consent to participate}

This study was part of a Quality Improvement Project to increase adherence to an evidence-based protocol of delayed cord clamping. Data was collected as part of routine delivery- and neonatal care, and was anonymised preanalysis. Hence, the study was approved as a service evaluation as defined by the Regional Committee for Medical and Health Research Ethics (2018/ 1755/REK midt) and waiver of individual patient informed consent was granted. It was approved by the Director of Clinic for Women, Children and Adolescents, Møre and Romsdal Hospital Trust, and by the institution's Privacy Ombudsman (ephorte reference 2018/1357-10).

\section{Consent for publication}

Not applicable.

\section{Competing interests}

The authors declare that they have no competing interests.

\section{Author details}

'Department of Obstetrics and Gynecology, Møre and Romsdal Hospital Trust, Åsehaugen 5, N-6017 Ålesund, Norway. ²Department of Pediatrics, Møre and Romsdal Hospital Trust, Ålesund Hospital, Ålesund, Norway. ${ }^{3}$ Department of Medicine and Healthcare, Møre and Romsdal Hospital Trust, Ålesund Hospital, Ålesund, Norway. ${ }^{4}$ Department of Health Sciences in Ålesund, Faculty of Medicine and Health Sciences, Norwegian University of Science and Technology (NTNU), Ålesund, Norway. ${ }^{5}$ Department of Research and Innovation, Helse Møre and Romsdal Hospital Trust, Ålesund, Norway.

\section{Received: 25 February 2020 Accepted: 19 August 2020}

Published online: 27 August 2020

\section{References}

1. Downey $\mathrm{CL}$, Bewley S. Historical perspectives on umbilical cord clamping and neonatal transition. J R Soc Med. 2012;105(8):325-9. https://doi.org/10 1258/jrsm.2012.110316

2. WHO. Guideline: Delayed Umbilical Cord Clamping for Improved Maternal and Infant Health and Nutrition Outcomes, vol. 26. Geneva: World Health Organization; 2014. Available from: https://www.who.int/nutrition/ publications/guidelines/cord_clamping/en/ Accessed 30 Apr 2019

3. White C. A Treatise on the Management of Pregnant and Lying-in Women and the Means of Curing, But More Especially of Preventing the Principal Disorders to which They are Liable, Together with Some New Directions Concerning the Delivery of the Child and Placenta in Natural Births, Illustrated with Cases, vol. 476: Charles Dilly; 1791. Available from: https:// books.google.no/books?id=tAqanQAACAAJ\&hl=no\&source=gbs_navlinks_s.
4. Sundström AK, Rosén D, Rosén KG. Fosterovervåking. 1st ed. Göteborg: Neoventa Medical AB; 2000.

5. Eikeland T, Haugeberg B, Henriksen T, Hjelle S, Yli B, Blix E, et al. Overvaking under fødsel - CTG, føtale blodprøvar, CTG + ST-analyse av foster-EKG. In: Norsk veileder i fødselshjelp. Oslo: Den norske legeforening; 2008. p. 90-7. Available from: https://www.legeforeningen.no/contentassets/04d0b3c134 ac4b12aa1a03c3a2666585/veileder-i-fodselshjelp-2008.pdf Accessed $30 \mathrm{Apr}$ 2019.

6. Wiberg N, Kallen K, Olofsson P. Delayed umbilical cord clamping at birth has effects on arterial and venous blood gases and lactate concentrations. BJOG. 2008;115(6):697-703. https://doi.org/10.1111/j.1471-0528.2008.01708.x.

7. Lundberg C, Öian P, Klingenberg C. Umbilical cord clamping at birth practice in Norwegian maternity wards. Tidsskr Nor Legeforen. 2013;133(22): 2369-72. https://doi.org/10.4045/tidsskr.12.0707.

8. McDonald SJ, Middleton P, Dowswell T, Morris PS. Effect of timing of umbilical cord clamping of term infants on maternal and neonatal outcomes. Cochrane Database Syst Rev. 2013;7:CD004074. https://doi.org/ 10.1002/14651858.CD004074.pub3.

9. Fogarty M, Osborn DA, Askie L, Seidler AL, Hunter K, Lui K, et al. Delayed vs early umbilical cord clamping for preterm infants: a systematic review and meta-analysis. Am J Obstet Gynecol. 2018;218(1):1-18. https://doi.org/10. 1016/j.ajog.2017.10.231.

10. WHO. Guidelines on Basic Newborn Resuscitation, vol. 61. Geneva: World Health Organization; 2012. Available from: http://www.who.int/maternal_ child_adolescent/documents/basic_newborn_resuscitation/en/ Accessed 30 Apr 2019.

11. European Resuscitation Council. Summary of the main changes in the Resuscitation Guidelines, vol. 24; 2015. https://cprguidelines.eu/sites/573 c777f5e61585a053d7ba5/assets/573c77d75e61585a083d7ba8/ERC_ summary_booklet_HRES.pdf Accessed 20 Oct 2017.

12. Sweet DG, Carnielli V, Greisen G, Hallman M, Ozek E, te Pas A, et al. European Consensus Guidelines on the Management of Respiratory Distress Syndrome - 2019 Update. Neonatology. 2019;115(4):432-50. https:/doi.org/ $10.1159 / 000499361$.

13. Katheria AC. Umbilical Cord Milking: A Review. Front Pediatr. 2018;6(335). https://doi.org/10.3389/fped.2018.00335.

14. Rabe H, Gyte GM, Diaz-Rossello JL, Duley L. Effect of timing of umbilical cord clamping and other strategies to influence placental transfusion at preterm birth on maternal and infant outcomes. Cochrane Database Syst Rev. 2019:9:Cd003248. https://doi.org/10.1002/14651858.CD003248.pub4.

15. Bhatt S, Polglase GR, Wallace EM, Te Pas AB, Hooper SB. Ventilation before Umbilical Cord Clamping Improves the Physiological Transition at Birth. Front Pediatr. 2014;2:113. https://doi.org/10.3389/fped.2014.00113.

16. Polglase GR, Blank DA, Barton SK, Miller SL, Stojanovska V, Kluckow M, et al. Physiologically based cord clamping stabilises cardiac output and reduces cerebrovascular injury in asphyxiated near-term lambs. Arch Dis Child Fetal Neonatal Ed. 2018;103(6):F530-F8. https://doi.org/10.1136/archdischild-2017-313657.

17. Manley BJ, Owen LS, Hooper SB, Jacobs SE, Cheong JLY, Doyle LW, et al Towards evidence-based resuscitation of the newborn infant. Lancet. 2017; 389(10079):1639-48. https://doi.org/10.1016/S0140-6736(17)30547-0.

18. Hooper SB, Polglase GR, te Pas AB. A physiological approach to the timing of umbilical cord clamping at birth. Arch Dis Child Fetal Neonatal Ed. 2015; 100(4):F355-60. https://doi.org/10.1136/archdischild-2013-305703.

19. Uwins C, Hutchon D. Delayed umbilical cord clamping after childbirth: potential benefits to baby's health. Ped Health Med Therapeut. 2014;5:16171. https://doi.org/10.2147/PHMT.S51867.

20. Boere I, Roest AA, Wallace E, Ten Harkel AD, Haak MC, Morley CJ, et al. Umbilical blood flow patterns directly after birth before delayed cord clamping. Arch Dis Child Fetal Neonatal Ed. 2015;100(2):F121-5. https://doi. org/10.1136/archdischild-2014-307144.

21. Erickson-Owens D, Mercer JS, Wang M. The Effects of Placental Transfusion on 12-Month Brain Myelin Content in Term Infants: A Randomized Controlled Trial. J Midwifery Womens Health. 2018;63(5):623-4. https://doi. org/10.1111/jmwh.12912.

22. Katheria A, Brown MK, Faksh A, Hassen KO, Rich W, Lazarus D, et al. Delayed Cord Clamping in Newborns Born at Term at Risk for Resuscitation: A Feasibility Randomized Clinical Trial. J Pediatr. 2017;187:313-7.e1. https://doi. org/10.1016/j.jpeds.2017.04.033.

23. Wyllie J, Ainsworth S. What is new in the European and UK neonatal resuscitation guidance? Arch Dis Child Fetal Neonatal Ed. 2016;101(5):F46973. https://doi.org/10.1136/archdischild-2015-309472. 
24. Mercer J, Erickson-Owens D, Skovgaard R. Cardiac asystole at birth: is hypovolemic shock the cause? Med Hypotheses. 2009;72(4):458-63. https:// doi.org/10.1016/j.mehy.2008.11.019.

25. Mercer JS, Erickson-Owens DA. Is it time to rethink cord management when resuscitation is needed? J Midwifery Womens Health. 2014;59(6):635-44. https://doi.org/10.1111/jmwh.12206.

26. Andersson O, Rana N, Ewald U, Malqvist M, Stripple G, Basnet O, et al. Intact cord resuscitation versus early cord clamping in the treatment of depressed newborn infants during the first 10 minutes of birth (Nepcord III) - a randomized clinical trial. Matern Health Neonatol Perinatol. 2019;5:15. https://doi.org/10.1186/s40748-019-0110-z

27. Brouwer E, Knol R, Vernooij ASN, van den Akker T, Vlasman PE, Klumper FJCM, et al. Physiological-based cord clamping in preterm infants using a new purpose-built resuscitation table: a feasibility study. Arch Dis Child Fetal Neonatal Ed. 2019. https://doi.org/10.1136/archdischild-2018-315483.

28. Katheria A, Poeltler D, Durham J, Steen J, Rich W, Arnell K, et al. Neonatal Resuscitation with an Intact Cord: A Randomized Clinical Trial. J Pediatr. 2016;178:75-80.e3. https://doi.org/10.1016/j.jpeds.2016.07.053.

29. Thomas MR, Yoxall CW, Weeks AD, Duley L. Providing newborn resuscitation at the mother's bedside: assessing the safety, usability and acceptability of a mobile trolley. BMC Pediatr. 2014;14:135. https://doi.org/10.1186/1471-243114-135.

30. Hutchon DJR. The role of mother's and father's voice and touch in improving neonatal transition at birth. 26th International Conference on Neonatology and Perinatology; 2018 Nov 15-17; Edinburgh, Scotland. J Neonatal Biol. 2018;7 https://www.longdom.org/conference-abstractsfiles/2167-0897-C3-013-002.pdf Accessed 21 Sept 2018.

31. Bergman NJ. The neuroscience of birth-and the case for Zero Separation. Curationis. 2014;37(2):1-4. https://doi.org/10.4102/curationis.v37i2.1440

32. Hutchon D, Bettles N. Motherside care of the term neonate at birth. Matern Health Neonatol Perinatol. 2016;2(1):5. https://doi.org/10.1186/s40748-0160034-9.

33. Norsk Resuscitatsjonråd. Resuscitering av nyfødte - algoritme [Flowsheet]. Oslo: Norsk Resuscitasjonsråd - NRR; 2015. Available from: https://nrr.org/ images/pdf/Nyfodte.pdf Accessed 20 Mar 2019.

34. Langley GJ, Moen RD, Nolan KM, Nolan TW, Norman CL, Provost LP. The improvement guide: a practical approach to enhancing organizational performance: 2nd ed. San Francisco: Wiley; 2009

35. Nyen B. Forbedringsarbeid og Statistisk Prosesskontroll (SPC). Bergen: Nasjonalt Kunnskapssenter for helsetjenesten; 2009. Available from: https:// www.fhi.no/publ/eldre/forbedringsarbeid-og-statistisk-prosesskontroll-spc-2. 0/ Accessed 1 Oct 2018

36. Perla RJ, Provost LP, Murray SK. The run chart: a simple analytical tool for learning from variation in healthcare processes. BMJ Qual Saf. 2011;20(1):4651. https://doi.org/10.1136/bmjas.2009.037895

37. Blank DA, Badurdeen S, Omar F, Kamlin C, Jacobs SE, Thio M, Dawson JA, et al. Baby-directed umbilical cord clamping: A feasibility study. Resuscitation. 2018;131:1-7. https://doi.org/10.1016/j.resuscitation.2018.07. 020.

38. Sawyer A, Ayers S, Bertullies S, Thomas M, Weeks AD, Yoxall CW, et al. Providing immediate neonatal care and resuscitation at birth beside the mother: parents' views, a qualitative study. BMJ OpenBMJ open. 2015;5(9): e008495. https://doi.org/10.1136/bmjopen-2015-008495.

39. Moore ER, Bergman N, Anderson GC, Medley N. Early skin-to-skin contact for mothers and their healthy newborn infants. Cochrane Database Syst Rev. 2016;11(11):CD003519-CD. https://doi.org/10.1002/14651858.CD003519. pub4.

40. Liu LY, Feinglass JM, Khan JY, Gerber SE, Grobman WA, Yee LM. Evaluation of Introduction of a Delayed Cord Clamping Protocol for Premature Neonates in a High-Volume Maternity Center. Obstet Gynecol. 2017;129(5): 835-43. https://doi.org/10.1097/aog.0000000000001987

41. Pantoja AF, Ryan A, Feinberg M, DeMarie M, Britton J, Liptsen E, et al. Implementing delayed cord clamping in premature infants. BMJ Open Quality. 2018;7(3):e000219. https://doi.org/10.1136/bmjoq-2017-000219.

42. Batey N, Yoxall CW, Fawke JA, Duley L, Dorling J. Fifteen-minute consultation: stabilisation of the high-risk newborn infant beside the mother. Arch Dis Child Educ Pract Ed. 2017;102(5):235-8. https://doi.org/10. 1136/archdischild-2016-312276.

43. Lapcharoensap W, Cong A, Sherman J, Schwandt D, Crowe S, Daniels K, et al. Safety and Ergonomic Challenges of Ventilating a Premature Infant
During Delayed Cord Clamping. Children. 2019;6(4):59. https://doi.org/10. 3390/children6040059.

44. Yoxall CW, Ayers S, Sawyer A, Bertullies S, Thomas M, Andrew DW, et al. Providing immediate neonatal care and resuscitation at birth beside the mother: clinicians' views, a qualitative study. BMJ Open. 2015;5(9):e008494 https://doi.org/10.1136/bmjopen-2015-008494.

\section{Publisher's Note}

Springer Nature remains neutral with regard to jurisdictional claims in published maps and institutional affiliations.
Ready to submit your research? Choose BMC and benefit from:

- fast, convenient online submission

- thorough peer review by experienced researchers in your field

- rapid publication on acceptance

- support for research data, including large and complex data types

- gold Open Access which fosters wider collaboration and increased citations

- maximum visibility for your research: over $100 \mathrm{M}$ website views per year

At BMC, research is always in progress.

Learn more biomedcentral.com/submissions 